\title{
Effects of a randomized controlled study on the behaviors of overweight schoolchildren
}

\author{
Efeitos de um estudo controlado randomizado sobre os comportamentos de escolares \\ sobrepesados
}

\begin{abstract}
AUTHOR'S
Anastácio Neco de Souza Filho ${ }^{1}$ (D)

Thaynã Alves Bezerra ${ }^{1}$ (D)

Paulo Felipe Ribeiro Bandeira ${ }^{2}$ (D)

Luciana Gatto Azevedo Cabral ${ }^{1}$ (D)

José Fernando Vila Nova de Moraes ${ }^{3}$

Clarice Maria de Lucena Martins ${ }^{1}$ (D)

Ferdinando Oliveira Carvalho ${ }^{3}$ (iD

1 Universidade Federal da Paraíba, Departamento

de Educação Física, João Pessoa, Paraíba, Brasil.

2 Universidade Regional do Cariri, Departamento

de Educação Física, Crato, Ceará, Brasil.

3 Universidade Federal do Vale do São Francisco,

Colegiado de Educação Física, Petrolina,

Pernambuco, Brasil.
\end{abstract}

\section{CORRESPONDING}

Anastácio Neco

anastaciosouzafilho@gmail.com

Federal University of Paraiba, Department

of Physical Education, João Pessoa, Paraíba,

Brazil.

DOI

$10.12820 /$ rbafs. $26 \mathrm{e} 0221$

\begin{abstract}
This study aimed to determine the effects of a school-based multi-component intervention on accelerometer-measured physical activity (PA) and sedentary behavior (SB) in schoolchildren overweight. This is a randomized controlled study with overweight schoolchildren, allocated to experimental group (EG; $\mathrm{n}=13 ; 7.6 \pm 0.8$ years; $42.9 \%$ boys) and control group (CG; $\mathrm{n}=17 ; 8.2 \pm 0.9$ years; $26.7 \%$ boys). The EG was submitted to a 10 -week school-based intervention, comprised of PA and psychological sessions (behavioral therapy), and nutritional guidance. The CG followed the daily routine of life. The time of PA and SB were measured using accelerometers used for seven days. To compare mean SB, moderate to vigorous physical activity (MVPA) and total physical activity (TPA), generalized estimation equations (GEE) were used. It was observed that the average time in MVPA and TPA increased significantly in EG at the weekend $(+40.9 \mathrm{~min} /$ day, $\mathrm{p}<0.001$; and $+51.6 \mathrm{~min}$ $/$ day, $\mathrm{p}=0.035$, respectively $)$ and at full week $(+62.9 \mathrm{~min} /$ day, $\mathrm{p}<0.001$; and $+225.09 \mathrm{~min} /$ day, $\mathrm{p}=$ 0.038 , respectively). There was no significant difference in time spent in $\mathrm{SB}$ after the intervention in both groups. Thus, it was concluded that the proposed school-based multicomponent intervention was effective in increasing levels of MVPA and TPA in overweight schoolchildren. This finding can optimize future interventions to promote a healthy lifestyle for schoolchildren in the school environment.
\end{abstract}

Keywords: Schoolchildren; Overweight; Physical activity; Sedentary behavior.

RESUMO

Este estudo objetivou analisar o efeito de uma intervenção multicomponente de base-escolar sobre os níveis de atividade física $(A F)$ e comportamento sedentário (CS) mensurados por acelerômetro, de escolares com sobrepeso. Trata-se de um estudo controlado randomizado com escolares sobrepesados alocadas em grupo experimental (GE; $n=13 ; 7,6 \pm 0,8$ anos; $42,9 \%$ meninos) e grupo controle ( $G C ; n=17 ; 8,2 \pm 0,9$ anos; 26,7\% meninos). O GE foi submetido a uma intervenção escolar de 10 semanas, composta por sessões de AF e psicológica (terapia comportamental) e orientação nutricional. O GC seguiu a rotina diária de vida. $O$ tempo de $A F$ e o CS foram medidos por meio de acelerômetros, utilizados durante sete dias. Para comparar o tempo médio de CS, atividade física moderada a vigorosa (AFMV) e atividade física total (AFT), foram utilizadas equaçōes de estimativa generalizadas (GEE). Observou-se que o tempo médio em AFMV e AFT aumentaram significativamente no GE no fim de semana (+ 40,9 min / dia, $p<0,001 ; e+51,6 \mathrm{~min}$ / dia, $p=0,035$, respectivamente) e na semana inteira $(+62,9 \mathrm{~min} / \mathrm{dia}, p<0,001 ; e+225,0 \mathrm{~min} /$ dia,$p=$ 0,038 , respectivamente). Não houve diferença significativa no tempo gasto em CS após a intervenção em ambos os grupos. Assim, conclui-se que uma intervenção multicomponente de base escolar proposta foi eficaz no aumento dos niveis de AFMV e AFT em escolares com sobrepeso. Esse achado pode otimizar futuras intervenções em promover um estilo de vida saudável de crianças no âmbito escolar.

Palavras-chave: Escolares; Excesso de peso; Atividade física; Comportamento sedentário.

\section{Introduction}

Overweight and obesity are important health problems due to their high prevalence, associated morbidities $^{1}$, spending on health services ${ }^{2}$ and difficulty in treatment ${ }^{3}$. Additionally, overweight children are physically less active ${ }^{4}$ and spend more time in sedentary behaviors $(\mathrm{SB})^{5}$, compared to normal-weight children.
However, those who are physically active ${ }^{6}$ have higher rates of quality of life, better mental, cardiometabolic, vascular and cardiorespiratory health ${ }^{7}$. Therefore, increasing physical activity (PA) levels and reducing the time being sedentary may promote positive changes in clinical outcomes related to overweight and obesity, improving children's quality of life? 
Interventions focused on promoting health outcomes in overweight children showed null or positive effects of low magnitude and short duration ${ }^{8,9}$. This is believed to be due to the unilateral approach used in several interventions, based on the single promotion of PA, or nutritional guidelines, or psychological therapies to promote positive changes on multifactorial etiology outcomes, what might compromise its effectiveness. In addition, interventions proposed within the school environment may be more promising, given that the school is recognized as an essential environment to promote children's healthy behaviors, considering its pre-planned, segmented, and supervised structure ${ }^{10}$. Moreover, for low-income children, whose prevalence of obesity is increasing, opportunities for PA outside of school are limited.

In this sense, considering that excess body weight in childhood is multifactorial, programs to promote $\mathrm{PA}$ and reduce $\mathrm{SB}$ should be multicomponent focused on PA, nutrition guidelines, and behavioral therapies, accessible to low-income families, applicable in the school environment and of low cost to the government ${ }^{11}$. Additionally, for low-income schoolchildren, school-based interventions play a fundamental role in generating opportunities for a healthy lifestyle, given that for this population, school is usually the only environment where children can accumulate $\mathrm{PA}^{12}$.

Thus, in this research, a multicomponent intervention model was proposed, in the school context (postschool timetable), with all the activities proposed being developed in the school itself, with a playful character (popular games) of easy application, performed in the post-school period, involving the family and different education and health professionals, teachers, parents, and schoolchildren. Thus, this study aimed to determine the effects of a school-based multi-component intervention on accelerometer-measured PA and SB in overweight schoolchildren.

\section{Methods}

This was a randomized controlled study, based on data analysis from the Program of Physical, Nutritional, and Psychological Activities in Overweight Schoolchildren - PANPES. PANPES evaluated the effectiveness of a multicomponent intervention on biological and behavioral factors of schoolchildren with excess body weight, enrolled in schools in peripheral neighborhoods, and with low HDI (Human Development Index) in the city of Petrolina, Permanbuco.
PANPES was approved by the Human Research Ethics Committee at local University (protocol n. 1.311.598) and registered with clinicaltrials.gov (NCT03041142). All schoolchildren who participated in the study were authorized by their parents or guardians, who signed the consent form.

The sample comprised schoolchildren from six to nine years of age with excess body weight, regularly enrolled in elementary schools, from the public municipal network of Petrolina, Permanbuco. The city of Petrolina is located in the Pernambuco hinterland, with an HDI of 0.69 and a population of approximately 350.000 inhabitants. In 2015 (year of assessment) the city had 79 municipal public schools.

Initially, schools with at least 100 children regularly enrolled with indoor court, and located on the outskirt of the city were selected. Based on these criteria, eight schools were considered eligible for initial screening, totaling a population of 2.231 schoolchildren.

Then, the number of children who should be evaluated for the diagnosis of excess body weight was determined. The product of the number of students enrolled by the prevalence of overweight in the Northeast was considered $^{13}: 2.231 \times 43.5 \%=960$. This number was divided among the eight schools considered eligible, totaling 122 children per school. Among the schools that were identified with at least 30 overweight schoolchildren $(n=2)$, one was drawn to be the control group and the other, the intervention group. To participate in the study, children would need to be regularly enrolled, be between 6 and 9 years old, and be classified as overweight.

The sample calculation was performed using the GPower 3.0.10 software, considering a power of 0.80 , an effect size of 0.3 , a probability of 5\%, totaling 24 schoolchildren for each group. To this value, $25 \%$ was added to compensate for possible losses and refusals, totaling 30 children per group. The allocation of children in the control and experimental group was based on a 1:1 ratio, randomly. There was no blinding during this process, neither for researchers nor for participants. The experimental group underwent a multicomponent intervention, carried out by two teachers and six Physical Education students, three nutritionists and one psychologist, and eight psychology students, for 10 weeks, with three weekly sessions (Tuesdays, Thursdays, and Saturdays).

The weekly sessions were aimed at schoolchildren and corresponded to 60 minutes of physical activities, 
based on popular games and play. For children, PA was performed 3 times a week. In addition, on weekends, the sessions were aimed at children and mothers. They consisted of 60 minutes of PA, 60 minutes of guidance on healthy eating, and 120 minutes of psychological therapies for behavioral changes. The mothers participated in aerobic gymnastics sessions (60 minutes / session), nutritional guidance (duration of 60 minutes / session) and sessions on behavior change (120 minutes / session) - Chart 1.

Physical education professionals performed physical activities in the school's multi-sport court, lasting one hour on weekdays and weekends. To keep the schoolchildren physically active for as long as possible, intervals of approximately two minutes for water intake between each activity were timed, resulting in a total time of six minutes throughout the session. Thus, thirty sessions of PA were carried out with the schoolchildren over the course of four months of intervention. At the weekend, schoolchildren and mothers participated in physical activities, and the children followed the same schedule of activities proposed for weekdays. For the mothers, aerobic gymnastics and functional training programs were developed, with a duration of fifty minutes each session.

In nutritional guidance sessions on healthy eating with schoolchildren, activities were developed on the importance of healthy eating. Thus, the schoolchildren got to know the group that each food is part of and the diversity of existing fruits and vegetables. In addition, practical activities were carried out to prepare a healthy snack. Finally, schoolchildren were encouraged to reproduce the knowledge acquired in the family environment, encouraging the whole family to adhere to healthier eating habits.

With mothers, nutrition professionals developed activities emphasizing nutritional needs for the children's age group, considering the ideal foods to be consumed every hour of the day. In addition, a debate was held about the group to which each food belongs and the formulation of a diet according to financial conditions. In addition, a cookbook was prepared with healthier foods, fruits, and typical dishes from the region.

Lifestyle changes were the main theme of behavioral therapies that were part of the intervention of psychology professionals. The children were divided into two groups to facilitate psychological monitoring, receiving the same guidelines and with the same duration (120 minutes) in each session. The meetings took place once a week, on Saturdays, with activities and dynamics that aimed to encourage adherence to healthy habits, considering the dietary aspects and the practice of physical activities, decrease screen time (television, cell phone, computer, etc.) throughout the week. The therapies were developed in a playful way (games, scavenger hunts, etc.), covering the entire children's universe.

With mothers, therapies had a strong motivational aspect, with parental relationships being one of the central themes of the intervention. Thus, activities were proposed so that mothers should be role models for their schoolchildren in the family environment, aiming positively change in the lifestyle of the whole family. During the sessions, the mothers were challenged to be engaged in healthy activity (e.g., practice physical activities and decreased time in CS) during the week, alone, or with their children. Throughout the intervention, mothers were divided into two smaller groups to ensure greater control over the activities carried out and make them feel more comfortable talking about themselves and their children. Both groups received the same guidelines and the same duration of the session (120 minutes) each. At each meeting, there was an evaluation of the activity proposed for the previous week (Chart 1).

The measurements of body mass $(\mathrm{kg})$ and height (cm) followed the standardization of the World Health Organization $(\mathrm{WHO})^{14}$. Body mass was measured with the schoolchildren standing, barefoot, and using light clothing, on a digital scale, brand Wiso ${ }^{\circledR}$, model W801, with an accuracy of up to $100 \mathrm{~g}$. Height was measured using a stadiometer attached to the scale, with $0.1 \mathrm{~cm}$ precision, taking the vertex and plantar region as a reference point. Both measures were performed in triplicate, with the median being adopted for the purpose of final results. The body mass index (BMI = body mass $[\mathrm{kg}] /$ height $\left[\mathrm{m}^{2}\right]$ ) was classified according to WHO criteria ${ }^{15}$. Schoolchildren who presented values above the 85 th percentile for BMI were considered overweight.

PA and SB were measured using ActiGraph GT3X + accelerometers (ActiGraph ${ }^{\circledR}, \mathrm{USA}$ ). The schoolchildren were instructed to use the accelerometer affixed to the waist for seven consecutive days, being withdrawn in the activities of fighting with falls, water, and during night sleep. Data were collected at a sampling rate of $80 \mathrm{~Hz}$ and epochs of 15 seconds $^{16}$. To reduce the data, the ActiLife 6.12 software was used, adopting the fol- 
Chart 1 - Outline of the research.

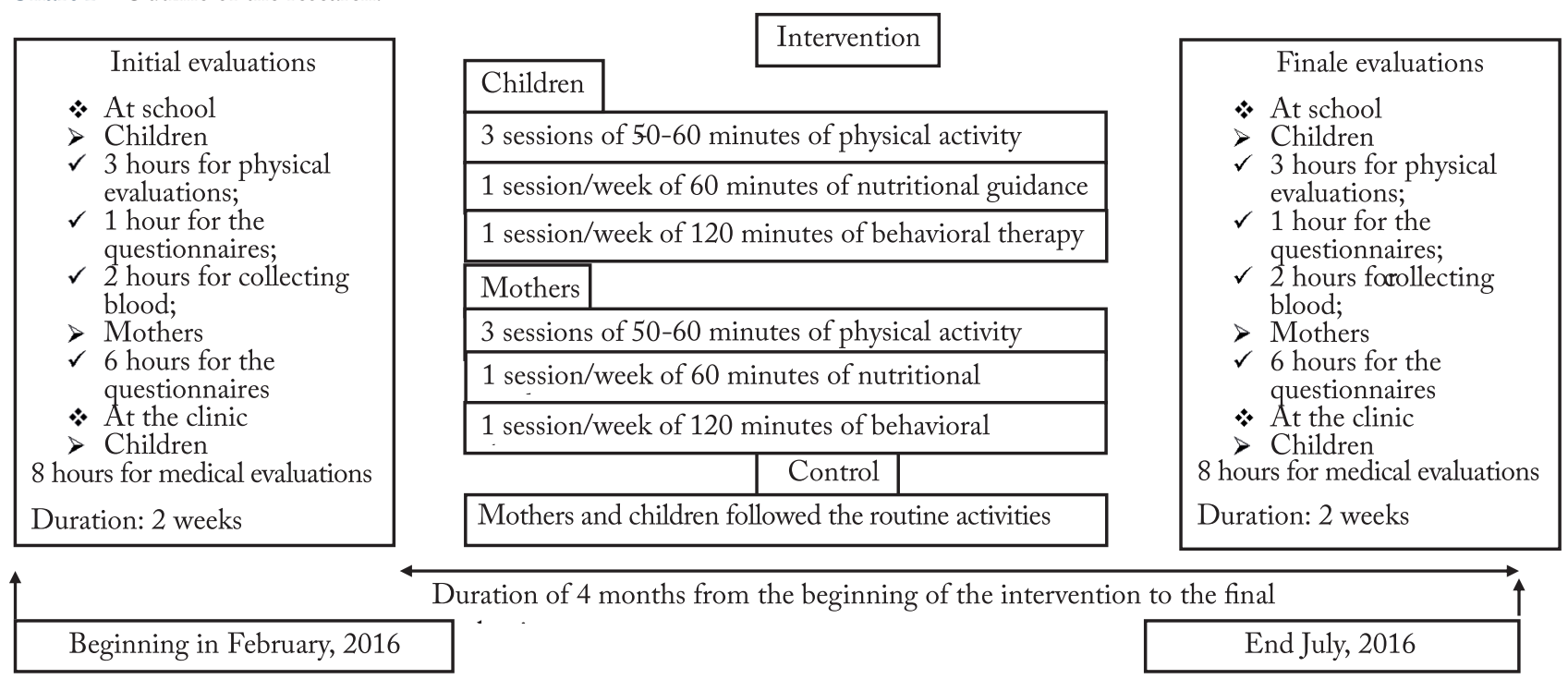

lowing criteria: valid days of use (three days a week and at least one weekend day); time of use (with at least 10 hours/day (06: $00 \mathrm{~h}$ to 00 : $00 \mathrm{~h}$ ); time of non-use (10 or more consecutive minutes of zero counts ${ }^{17}$.

The average time spent in SB, PA moderate to vigorous (MVPA), and total (TPA) intensity was obtained by the weighted average of minutes/day. For such definitions, the cut-off point established by Evenson ${ }^{18}$ was adopted. $\mathrm{PA}$ and $\mathrm{SB}$ were analyzed as the average time spent in the week, not over the weekend and the full week.

Baseline data collection was carried out in February 2016 and repeated at the end of the intervention, in June of the same year. All evaluations were carried out in the school environment, on Saturdays and in the afternoon. The collection and evaluation team consisted of professionals from physical education, nutrition, and psychology and was previously trained and followed a protocol proposed for the study, under the supervision of the responsible researcher.

The data were analyzed in accordance with the intention to treat principle. Thus, descriptive statistics of mean and standard deviation were used to describe the variables analyzed. To evaluate the influence of the effect of the intervention on the mean values of the AFT, AFMV, and CS of the students for the days of the week and weekends for 3 months, Generalized Estimation Equation Models (GEE) were constructed to assess the effect of the intervention in the time factor (pre and post-test) and in the group factor (experimental and control group). These models are suitable for continuous responses and repeated measures, re- flecting the relationship between dependent and independent variables, considering the correlation between measures for each moment. In addition, GHG models do not require the assumption of normality. For this study, the correlation matrix chosen was the autoregressive one, given that the measures in question have an autoregressive relationship as a function of time. To choose the correlation structure, the quasi-likelihood criterion was used under the independence model (Quasi-likelihood under the Independence model Criterion - QIC). Lower QIC value18 indicated the best correlation matrix to be chosen for the model. Therefore, the gamma family, the log link function, and the autoregressive correlation (AR) matrix were used for all the models. The coefficients $(\beta)$ were estimated for continuous data for all models, besides the respective confidence intervals. The analyzes were performed in Statistical Package for Social Sciences - SPSS (version 26.0 for Windows), and the level of significance was set at $\mathrm{p}<0.05$.

\section{Results}

A total of 60 schoolchildren were invited to participate in the program, however only 30 children (EG, $\mathrm{n}=12$ and $C G, n=18$ ) started the study (Figure 1).

Before intervention the children's mean age was 7.6 \pm 0.8 years in the EG and $8.2 \pm 0.9$ years in the CG. It $53 \%$ of male participants in EG, and the $81.2 \%$ of female participants in the control group. The BMI was $23.3 \pm 3.2$ for EG and $21.7 \pm 2.4$ for CG. There was homogeneity of the variables between both groups be- 
Figure 1 - Flowchart of the study's sampling process.

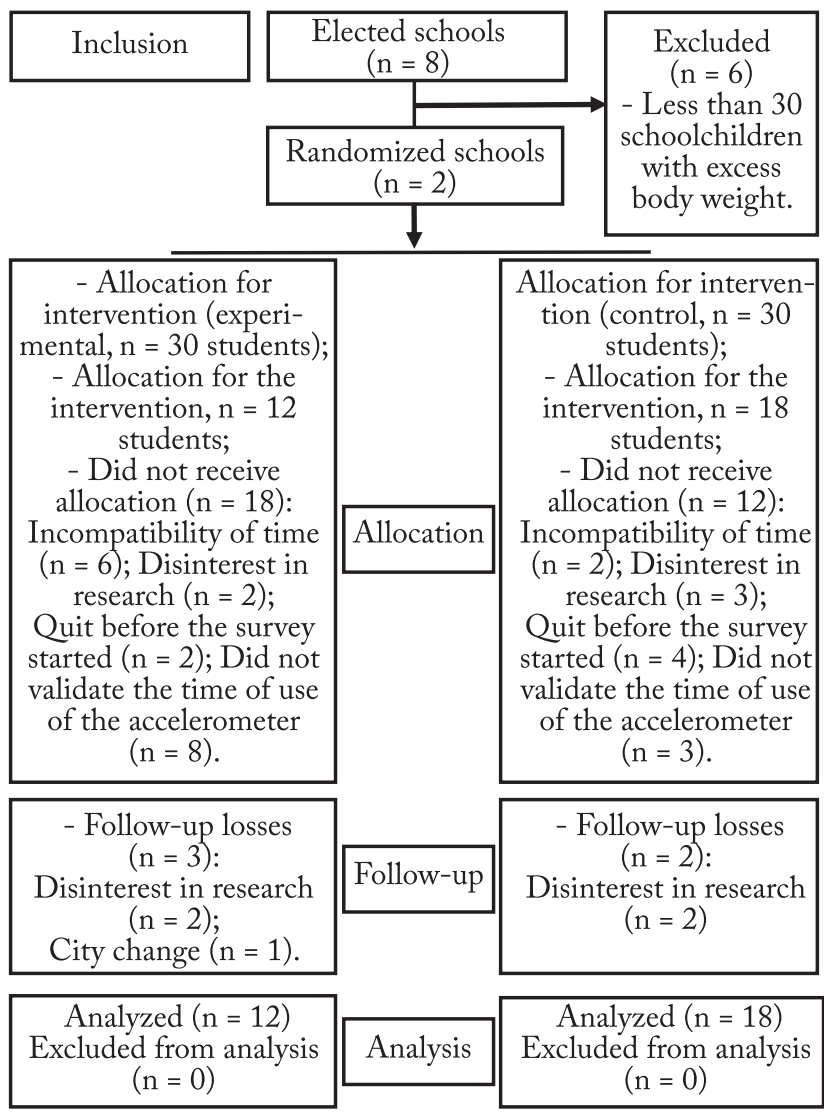

fore intervention (Table 1).

The effect of the interaction time $\mathrm{x}$ group on $\mathrm{SB}$, MVPA, and TPA, in the week days, weekend days and the whole week are shown in Table 1 . After the intervention the EG increased significantly in the mean time spent on MVPA and TPA on weekend days ( $\mathrm{p}<$ $0.001 ; \mathrm{p}=0.035$, respectively) and the full week $(\mathrm{p}<$ $0.001 ; \mathrm{p}=0.038$, respectively).

\section{Discussion}

The findings of this study demonstrated that the multicomponent intervention was effective in increasing the time of MVPA and TPA of schoolchildren with excess body weight. However, it has not been effective in reducing the time spent on SB.

The children in the EG showed an increase of approximate $50 \mathrm{~min} /$ day in time spent in MVPA at the weekend days. This increase is an important result from the point of view of public health, considering that it represents $83 \%$ of the recommended time for practicing PA for children and adolescents. The benefits of increased time in PA in overweight children have already been evidenced ${ }^{19}$, reinforcing its importance in
Table 1 - Analysis of the interaction between time and group for the variables average daily time spent total, moderate to vigorous physical activity and sedentary time of children aged 6 to 9 years, with excess body weight, in 2015 .

\begin{tabular}{|c|c|c|c|}
\hline Variavel & Experimental & Control & \multirow{2}{*}{$\mathrm{p}^{*}$} \\
\hline SB-wk & Mean (IC95\%) & Mean (IC95\%) & \\
\hline T0 & $420.8(373.3 ; 469.0)$ & $371.2(335.9 ; 410.3)$ & 0.638 \\
\hline $\mathrm{T} 1$ & $338.8(300.6 ; 381.8)$ & $353.0(309.9 ; 402.1)$ & 1.00 \\
\hline \multicolumn{4}{|c|}{ MVPA-wk } \\
\hline T0 & $36.0(26.8 ; 48.3)$ & $23.9(17.7 ; 32.2)$ & 0.386 \\
\hline $\mathrm{T} 1$ & $42.0(31.0 ; 57.8)$ & $28.6(22.6 ; 36.2)$ & 0.409 \\
\hline \multicolumn{4}{|l|}{ TPA-wk } \\
\hline T0 & $447.5(383.0 ; 523.0)$ & $438.4(401.3 ; 478.8)$ & 1.00 \\
\hline $\mathrm{T} 1$ & $409.2(357.3 ; 468.5)$ & $458.0(423.0 ; 495.2)$ & 0.907 \\
\hline \multicolumn{4}{|l|}{ SB-wkn } \\
\hline T0 & $358.2(301.1 ; 426.2)$ & $302.4(273.3 ; 334.7)$ & 0.688 \\
\hline $\mathrm{T} 1$ & $299.2(259.3 ; 245.3)$ & $340.7(290.1 ; 400.4)$ & 1.00 \\
\hline \multicolumn{4}{|c|}{ MVPA-wkn } \\
\hline T0 & $34.4(22.5 ; 52.7)$ & $27.5(19.5 ; 38.9)$ & 1.00 \\
\hline $\mathrm{T} 1$ & $75.3(66.6 ; 85.2)$ & $26.7(17.7 ; 40.0)$ & $<0.001^{* *}$ \\
\hline \multicolumn{4}{|c|}{ TPA-wkn } \\
\hline T0 & $451.3(389.7 ; 523.0)$ & $460.0(415.0 ; 510.0)$ & 1.00 \\
\hline $\mathrm{T} 1$ & $514.2(483.0 ; 548.0)$ & $432.5(387.0 ; 483.5)$ & $0.035^{* *}$ \\
\hline \multicolumn{4}{|l|}{ SB total } \\
\hline T0 & $390.2(345.7 ; 440.6)$ & $360.2(333.6 ; 389.0)$ & 1.00 \\
\hline $\mathrm{T} 1$ & $483.2(392.2 ; 595.4)$ & $348.3(311.0 ; 391.0)$ & 0.088 \\
\hline \multicolumn{4}{|c|}{ MVPA total } \\
\hline T0 & $35.4(26.0 ; 49.0)$ & $25.0(18.4 ; 33.3)$ & 0.748 \\
\hline $\mathrm{T} 1$ & $87.0(63.0 ; 119.2)$ & $28.1(22.0 ; 36.5)$ & $<0.001^{* *}$ \\
\hline \multicolumn{4}{|c|}{ TPA total } \\
\hline T0 & $459.0(406.0 ; 519.0)$ & $443.0(406.0 ; 483.0)$ & 1.00 \\
\hline $\mathrm{T} 1$ & $684.0(540.2 ; 866.3)$ & $454.0(419.0 ; 491.4)$ & $0.038^{* *}$ \\
\hline
\end{tabular}

$\mathrm{SB}=$ sedentary behavior; $\mathrm{MVPA}=$ moderate to vigorous physical activity; TPA = total physical activity; total = week days + weekend days; $\mathrm{p}=0.05 ;$ *GEE; T0 = pre- intervention; $\mathrm{T} 1$ = post- intervention; **level of significance of $5 \%$.

the treatment of health problems caused by overweight and obesity.

The prevalence of overweight and physical inactivity has been higher in the poorest families, so this type of intervention can be a feasible strategy to increase PA in poorer children with excess body weight. In practice, this result demonstrates that this type of intervention can be a means of including low-income children and family members, in spaces for structured and unstructured community PA. Therefore, the displacement to practice places far from home can be minimized, which tends to avoid expenses with transportation and food, and exposure to risks due to insecurity ${ }^{20}$.

It is also worth mentioning the participation of mothers as part of the intervention actions, which 
seems to be an approach to consider since the social support of parents has been shown to be a decisive factor in the adoption and maintenance of PA in children and adolescents ${ }^{21}$. In addition, the family can be an important factor in interventions aimed at increasing children's PA levels ${ }^{22}$, given that the family can support, encourage, model, and structure engagement in healthy behaviors of children ${ }^{23}$.

The increase in MVPA time at the weekend shows that the weekend can be a strategic period of the week for promoting PA in children. In fact, this can avoid possible barriers related to parents' work during the week, reinforcing the presence of parents with children in activities.

In general, interventions with overweight children have focused on systematic physical exercise, being carried out in clinics, hospitals, and universities, not involving family members and children in the same activity session, which could explain the absence of significant effects or effects of low magnitude and duration, on the practice of $\mathrm{PA}$ in this population ${ }^{9}$. Interventions carried out in low-income countries, focusing on increasing the time spent in PA, have demonstrated the potential to increase this population's daily levels of PA, especially in school-aged children ${ }^{24}$. However, methodological advances need to be implemented so that general conclusions can be made about the effectiveness of such interventions ${ }^{25}$.

The effect of the intervention in increasing the average time of TPA, both during the full week and at the weekend, demonstrates that this type of intervention in the school environment can be an important means for school-aged children to reach the recommended PA throughout the week ${ }^{26}$. A probable explanation for the finding may have been the way in which psychology counseling activities were planned and conducted, and the practical activities provided by physical education professionals. Furthermore, nutritional guidelines, one more factor for a healthier lifestyle could be contemplated, as suggested by Nishtar et al. ${ }^{11}$. In this sense, it is believed that the increase in PA time was the result of a joint proposal for a change in lifestyle. In this context, children and parents were encouraged and advised to perform physical activities of various kinds, outside the intervention environment, during activities carried out at school, and leisure activities in the community throughout the week. In fact, the direct participation of the family in the context of the intervention may have been an important factor for the children to increase the average daily time at this intensity.

Regarding the time spent in $\mathrm{SB}$, no significant changes were observed in both groups after the intervention. Other previously performed interventions showed similar results ${ }^{27}$, demonstrating that new intervention strategies need to be better planned, so that, in fact, this behavior change takes place ${ }^{28}$. It seems that $\mathrm{SB}$ has its own mechanisms and determinants, which are likely to differ from the PA proposed in the intervention ${ }^{29}$. Additionally, overweight children tend to spend more time in SB when compared to children with normal weight ${ }^{5}$.

Studies that aimed to modify time in specific SB, using different contexts such as schools, community, homes, and pediatric clinics, have shown promising results $^{30}$. Therefore, multiple strategies of intervention are being carried out, ranging from the objective monitoring of the total hours of TV time during the day, to the removal of electronic devices ( $\mathrm{TV}$, video game, stereo) from specific environments in the residence. Counseling activities in communities, schools, and pediatric centers have been other strategies used in these studies ${ }^{30}$.

The intervention had limitations that should be considered: the non-monitoring of students after the intervention, a fact that could reveal the real effects of the intervention on the students' behavior; The non-involvement of parents in weekly activities, which can somehow explain the lack of effect of the intervention, on the level of PA of students at that time of the week. Strengths include: having been a multi-component intervention and multi-professional; having involved children and mothers in the same intervention; having used popular games and games as content for practical activities; have occurred in the school environment; performed in the extracurricular period; have occurred in the week and at the weekend. These characteristics underscore the ecological value of the present intervention.

The school-based multicomponent intervention was effective to increase the time of practicing MVPA and TPA of schoolchildren with excess body weight. However, it has not been effective in reducing the time spent in SB. In this way, the implementation of multicomponent interventions in schools can be a strategy for changes in the levels of PA of overweight students. Public health and education managers must be aware of these findings because interventions with a multicomponent approach in the school environment can be important to increase the time of exposure of students to PA. 


\section{Conflict of interest}

The authors declare no conflict of interest.

\section{Author's contributions}

Souza Filho NA and Bezerra TA, participated in the initial conception of the study, data collection, data analysis, manuscript writing. Bandeira PFR and Cabral LGA, participated in data analysis and critical review of the text. Moraes JFVN, participated in the initial conception of the study and critical review of the text. Martins CML, participated in data analysis and critical review of the text. Carvalho FO, participated in the initial conception of the study, data collection, data analysis, manuscript writing and critical review of the text.

\section{References}

1. Afshin A, Forouzanfar MH, Reitsma MB, Sur P, Estep K, Lee A, et al. Health effects of overweight and obesity in 195 countries over 25 years. N Engl J Med. 2017;377(1):13-27.

2. Gonzaga N, Sena A, Coura A, Dantas F, Oliveira R, Medeiros C. Sleep quality and metabolic syndrome in overweight or obese children and adolescents. Rev. de Nutr. 2016;29:377-89.

3. Wang YC, McPherson K, Marsh T, Gortmaker SL, Brown M. Health and economic burden of the projected obesity trends in the USA and the UK. The Lancet. 2011;378(9793):815-25.

4. Pereira S, Gomes TN, Borges A, Santos D, Souza M, dos Santos FK, et al. Variability and stability in daily moderateto-vigorous physical activity among 10 year old children. International journal of environmental research and public health. 2015;12(8):9248-63.

5. Mushtaq MU, Gull S, Mushtaq K, Shahid U, Shad MA, Akram J. Dietary behaviors, physical activity and sedentary lifestyle associated with overweight and obesity, and their socio-demographic correlates, among Pakistani primary school children. Int. J. Behav. Nutr. Phys. Act. 2011;8(1):130.

6. Schneller MB, Duncan S, Schipperijn J, Nielsen G, Mygind E, Bentsen P. Are children participating in a quasi-experimental education outside the classroom intervention more physically active? BMC Public Health. 2017;17(1):523.

7. García-Hermoso A, Ramírez-Vélez R, Saavedra JM. Exercise, health outcomes, and pediatric obesity: A systematic review of meta-analyses. J Sport Sci Med.2019;22(1):76-84.

8. Nooijen CFJ, Galanti MR, Engström K, Möller J, Forsell Y. Effectiveness of interventions on physical activity in overweight or obese children: a systematic review and meta-analysis including studies with objectively measured outcomes. Obes Rev. 2017;18(2):195-213.

9. Metcalf B, Henley W, Wilkin T. Effectiveness of intervention on physical activity of children: systematic review and meta-analysis of controlled trials with objectively measured outcomes (EarlyBird 54). BMJ: Br Med J. 2012;345:e5888.

10. Adom T, Kengne AP, De Villiers A, Puoane T. Association between school-level attributes and weight status of Ghanaian primary school children. BMC Public Health. 2019;19(1):577.

11. Nishtar S, Gluckman P, Armstrong T. Ending childhood obesity: a time for action. Lancet (London, England). 2016;387(10021):825-7.
12. Di Cesare M, Sorić M, Bovet P, Miranda JJ, Bhutta Z, Stevens GA, et al. The epidemiological burden of obesity in childhood: a worldwide epidemic requiring urgent action. BMC med. 2019;17(1):212.

13. IBGE. Pesquisa de Orçamentos Familiares-POF. Antropometria e Estado Nutricional de Crianças,Adolescentes e Adultos no Brasil. In: Ministério do Planejamento OeG, editor.: IBGE Rio de Janeiro; 2010. p. 130.

14. WHO. Physical status: the use and interpretation of anthropometry: report of a WHO Expert Committee. Geneva; 1995. 1995;854.

15. de Onis M, Onyango AW, Borghi E, Siyam A, Nishida C, Siekmann J. Development of a WHO growth reference for school-aged children and adolescents. Bull World Health Organ. 2007;85(9):660-7.

16. Migueles JH, Cadenas-Sanchez C, Ekelund U, Delisle Nyström C, Mora-Gonzalez J, Löf M, et al. Accelerometer Data Collection and Processing Criteria to Assess Physical Activity and Other Outcomes: A Systematic Review and Practical Considerations. Sports med. 2017;47(9):1821-45.

17. Engelen L, Bundy AC, Naughton G, Simpson JM, Bauman $A$, Ragen J, et al. Increasing physical activity in young primary school children - it's child's play: A cluster randomised controlled trial. Prev. Med. 2013;56(5):319-25.

18. Evenson KR, Catellier DJ, Gill K, Ondrak KS, McMurray RG. Calibration of two objective measures of physical activity for children. J. Sports Sci. 2008;26(14):1557-65.

19. Branscum P, Sharma M. After-School Based Obesity Prevention Interventions: A Comprehensive Review of the Literature. Int. J. Environ. Res. Public Health. 2012;9(4).

20. Mead E, Brown T, Rees K, Azevedo LB, Whittaker V, Jones $\mathrm{D}$, et al. Diet, physical activity and behavioural interventions for the treatment of overweight or obese children from the age of 6 to 11 years. Cochrane Database Syst. Rev. 2017(6).

21. Golley RK, Hendrie GA, Slater A, Corsini N. Interventions that involve parents to improve children's weight-related nutrition intake and activity patterns - what nutrition and activity targets and behaviour change techniques are associated with intervention effectiveness? Obes. Rev. 2011;12(2):114-30.

22. Hu D, Zhou S, Crowley-McHattan ZJ, Liu Z. Factors That Influence Participation in Physical Activity in School-Aged Children and Adolescents: A Systematic Review from the Social Ecological Model Perspective. Int. J. Environ. Res. Public Health. 2021;18(6):3147.

23. Rhodes RE, Guerrero MD, Vanderloo LM, Barbeau K, Birken CS, Chaput J-P, et al. Development of a consensus statement on the role of the family in the physical activity, sedentary, and sleep behaviours of children and youth. Int J Behav Nutr Phys Act. 2020;17(1):74.

24. Craike M, Wiesner G, Hilland TA, Bengoechea EG. Interventions to improve physical activity among socioeconomically disadvantaged groups: an umbrella review. Int J Behav Nutr Phys Act. 2018;15(1):43.

25. Klingberg S, Draper C, Micklesfield L, Benjamin Neelon S, Sluijs E.Childhood Obesity Prevention in Africa:A Systematic Review of Intervention Effectiveness and Implementation. Int. J. Environ. Res. Public Health. 2019;16(7).

26. WHO. Recomendaciones mundiales sobre actividad física para la salud. Geneva: WHO Library Cataloguing-inPublication; 2010.

27. Wahi G, Parkin PC, Beyene J, Uleryk EM, Birken CS. Effectiveness of Interventions Aimed at Reducing Screen Time in Children: A Systematic Review and Meta-analysis of Randomized Controlled Trials. Arch Pediatr Adolesc Med. 2011;165(11):979-86. 
28. Friedrich RR, Polet JP, Schuch I, Wagner MB. Effect of intervention programs in schools to reduce screen time: a meta-analysis. J. . Pediatr. 2014;90(3):232-41.

29. Tremblay MS, Aubert S, Barnes JD, Saunders TJ, Carson V, Latimer-Cheung AE, et al. Sedentary Behavior Research Network (SBRN) - Terminology Consensus Project process and outcome. Int. J. Behav. Nutr. Phys. Act. 2017;14(1):75.
30. Biddle SJH, Petrolini I, Pearson N. Interventions designed to reduce sedentary behaviours in young people: a review of reviews. Br. J. Sports Med. 2014;48(3):182.

\section{Ouote this article as:}

Souza Filho AN, Bezerra TA, Bandeira PFR, Cabral LGA, Moraes JFVN, Martins CML, Carvalho FO. Effects of a randomized controlled study on the behavior of overweight schoolchildren. Rev Bras Ativ Fis Saúde. 2021;26:e0221. DOI: 10.12820/rbafs.26e0221 